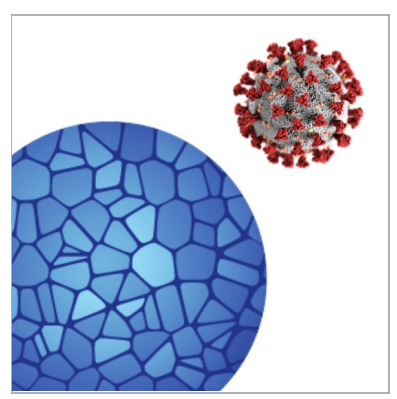

SEP 17, 2020

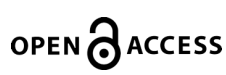

DOI:

dx.doi.org/10.17504/protocol s.io.bjm6kk9e

Protocol Citation: Peter Szabo, Steven Wells, Peter A. Sims, Donna Farber 2020. COVID Blood Processing for scRNAseq. protocols.io

https://dx.doi.org/10.17504/p rotocols.io. bjm6kk9e

License: This is an open access protocol distributed under the terms of the Creative Commons Attribution License, which permits unrestricted use, distribution, and reproduction in any medium, provided the original author and source are credited

Protocol status: Working We use this protocol and it's working

Created: Aug 12, 2020

Last Modified: Sep 17, 2020

PROTOCOL integer ID: 40350

Keywords: SARS-CoV-2, COVID-19, lymphocytes, isolation, pan-mononuclear cells, human whole blood scRNAseq

\section{(3) COVID Blood Processing for scRNAseq}

$\rightarrow$ In 1 collection

Peter Szabo ${ }^{1}$, Steven Wells ${ }^{1}$, Peter A. Sims ${ }^{1}$, Donna Farber ${ }^{1}$

${ }^{1}$ Columbia University

Human Cell Atlas Method Development Community

Coronavirus Method Development Community

Peter Sims

\section{ABSTRACT}

This protocol describes the isolation of lymphocytes and pan-mononuclear cells from human whole blood for scRNAseq analysis.

\section{ATTACHMENTS \\ Columbia_Wells_COVID_B \\ lood_RosetteSep_Process \\ ing_for_scRNAseq.pdf}

\section{MATERIALS}

\section{MATERIALS}

88 Gibco $^{\text {TM }}$ DPBS no calcium no magnesium Thermo Fisher Scientific Catalog \#14190144

88 Penicillin-Streptomycin-Glutamine (100X) Thermo Fisher Catalog \#10378016

\& UltraPure $^{\text {TM }}$ 0.5M EDTA, pH 8.0 Thermo Fisher Catalog \#15575020

Thermo Scientific $^{\text {TM }}$ Nunc $^{\text {TM }} 50 \mathrm{~mL}$ Conical Sterile Polypropylene Centrifuge Tubes Fisher Scientific Catalog \#12-565-271

$885 \mathrm{~mL}$ Falcon $^{\text {TM }}$ Round-Bottom Polypropylene Test Tubes Fisher Scientific Catalog \#14-959-11A

88 Biotin anti-human CD235ab Antibody BioLegend Catalog \#306618

88 Biotin anti-human CD66b Antibody BioLegend Catalog \#305120

88 BioMag® Plus Streptavidin Bangs Laboratories Catalog \#BP628

88 Corning $^{\text {TM }}$ Externally Threaded Cryogenic Vials Fisher Scientific Catalog \#09-761-71

88 CryoStor CS10 100ML Fisher Scientific Catalog \#NC9930384

$8 \mathrm{Gibco}^{\mathrm{TM}}$ Fetal Bovine Serum qualified Australia Fisher Scientific Catalog \#10-099-141

88 Ficoll-Paque $^{\text {TM }}$ PLUS Media Fisher Scientific Catalog \#45-001-749

88 Human TruStain FcX ${ }^{\mathrm{TM}}$ BioLegend Catalog \#422302

88 NC-Slide A8 ${ }^{\text {TM }}$ box with 25 Slides Chemometec Catalog \#942-0003

88 Solution 13 AO - DAPI Chemometec Catalog \#910-3013

88 Dead Cell Removal Kit Miltenyi Biotec Catalog \#130-090-101

88 MS Columns Miltenyi Biotec Catalog \#130-042-201

88 RosetteSep $^{\mathrm{TM}}$ Human Granulocyte Depletion Cocktail Stemcell Technologies Catalog \#15624

\section{Equipment}

- Centrifuge

- Cell Counter - NC-3000

- EasyEights ${ }^{\mathrm{TM}}$ EasySep $^{\mathrm{TM}}$ Magnet (Stemcell Technologies, Cat. No.: 18103) 
Equipment

\section{EasyEights $^{\mathrm{TM}}$ EasySep $^{\mathrm{TM}}$ Magnet}

Magnet for column-free immunomagnetic separation

EasySep

18103

https://www.stemcell.com/easyeights-easysep-magnet.html

- MACS Multistand (Miltenyi, Cat. No.: 130-108-934)

Equipment

\section{MACS MultiStand}

Separator for magnetic cell separation

MACS

\section{SAFETY WARNINGS}

(1) For hazard information and safety warnings, please refer to the SDS (Safety Data Sheet).

\section{Biosafety Notes}

- All materials required for sample processing are to be prepared in the biosafety cabinet before handling of blood samples.

- All blood sample manipulation takes place in a biosafety cabinet unless specifically stated.

- All centrifugation steps must take place in capped containers. Upon completion of a centrifugation step, return the capped container to the biosafety cabinet, remove all tubes, and spray and wipe them with $>70 \%$ ethanol before continuing to the next step.

\section{Preparing Buffer}

1 Create the following DPBS Solution-EDTA in a bottle of DPBS by using the table below:

\begin{tabular}{|l|l|l|l|}
\hline Component & Volume $(\mathrm{mL})$ & Starting Conc. & $\begin{array}{l}\text { Final } \\
\text { Conc. }\end{array}$ \\
\hline DPBS & 474 & - & \\
\hline FBS & 25 & $100 \%$ & $5 \%$ \\
\hline EDTA & 1 & $0.5 \mathrm{M}$ & $1 \mathrm{mM}$ \\
\hline
\end{tabular}


Table 1.

\section{Preparation of Blood}

$2 \quad$ Place sample box into biosafety cabinet.

3 Remove samples from the box and from the containment bags, discard bags, spray sample containers with $>70 \%$ ethanol and wipe down.

4 Record the total volume of whole blood to be processed in $\mathrm{mL}$.

5 Spin the whole blood $\because 400 \times \mathrm{g}, 20^{\circ} \mathrm{C}, 00: 10: 00$ in the anti-coagulant tubes and remove the plasma layer to cryovials. Be sure to not remove any red blood cells with the plasma. Add the same volume to all cryovials.

Record number of vials: and the volume per vial $\mathrm{mL}$.

Note

NOTE: Ensure that cryovials are decomtaminated prior to removal from the biosafety cabinet.

6 Add the same volume of DPBS Solution-EDTA as removed plasma back to the blood tube. Pipette to mix.

\section{RosetteSep and Ficoll-Paque}

Add $\triangle 50 \mu \mathrm{L}$ RosetteSep Cocktail/ $1 \mathrm{~mL}$ of blood directly to the blood tube. Pipette to mix.

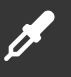

\section{8

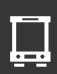
Inclubate samples at $8^{\circ}$ Room temperature

\section{for $00: 20: 00$}


11 Using the slow setting on the pipette gun, gently layer the blood/DPBS Solution-EDTA mixture on top of the \ $15 \mathrm{~mL}$ Ficoll-Paque Media PLUS . Take extra care not to disturb the blood-ficoll interface while layering. Disturbing the interface excessively prevents the mononuclear cells from becoming a clean layer.

NOTE: Centrifuge should be pre-warmed to $8^{\circ} 20^{\circ} \mathrm{C}$

13 Remove the mononuclear cell layer from each tube and transfer to a new $50 \mathrm{~mL}$ tube. Take extra care to avoid pulling cells from the ficoll layer (underneath the mononuclear cell layer) as this typically contains a lot of granulocytes. Pulling from the plasma layer is not an issue.

16 Remove the supernatant (caution: pellet may be loose), and resuspend the cell pellet in

\section{Cell Counting of COVID Samples}

17 Add $\triangle 0.05 \mathrm{~mL}$ sample , \ $0.05 \mathrm{~mL}$ DPBS, and $\triangle 0.005 \mathrm{~mL}$ Solution 13 to a $1.5 \mathrm{~mL}$ centrifuge tube, incubate for 
19 Aliquot $\mathbb{2} 0.01 \mathrm{~mL}$ sample to the well of a NC-Slide A8 and count on the NC-3000.

de

Record number and viability below, calculate total cells:

cell number: cells $/ \mathrm{mL}$, $\%$ viable

\section{Division of Sample for Analysis and Freeze-down}

20 Aliquot up to $2 \times 10^{7}$ cells to a $5 \mathrm{~mL}$ Falcon Round-Bottom tube and place $8^{8}$ On ice for subsequent sample clean-up (next section).

21 Freeze down up to $1 \times 10^{8}$ cells in approximately $1 \times 10^{7}$ aliquots ( $11 \mathrm{~mL}$ each) using Cryostor CS10 Medium, a Mr. Frosty, and a $8^{\circ}-80^{\circ} \mathrm{C}$ freezer.

Record the number of vials frozen: and the cells per cryovial frozen:

\section{Sample Clean Up for scRNAseq - CD66b and CD235ab removal}

22 Centrifuge the single cell suspension for $\because 400 \times \mathrm{g}, 4^{\circ} \mathrm{C}, 00: 05: 00$. 
Remove all the supernatant from the BioMag Plus Streptavidin Beads, remove from the magnet and resuspend the beads in \& $0.1 \mathrm{~mL}$ DPBS Solution-EDTA

centifuge for $400 \times \mathrm{g}, 4 \mathrm{c}, 00.05 .00$

31 Add $\triangle 3 \mathrm{~mL}$ DPBS to the tube and place on a magnet for 00:05:00

32 Remove supernatant from tube and transfer to a separate $5 \mathrm{~mL}$ Falcon Round Bottom tube.

\section{Sample Clean Up for scRNAseq - Dead Cell Removal}

33

Centrifuge the single cell suspension for $900 \mathrm{x} \mathrm{g}, 4^{\circ} \mathrm{C}, 00: 05: 00$, and discard supernatant. 
35 While the cell suspension is incubating, place an MS Column onto the MACS Multistand and rinse with

36 Post incubation, apply cell suspension to the MS Column and capture the flow through in a $5 \mathrm{~mL}$ Falcon Round Bottom tube.

37 Rinse with $\triangle 1.5 \mathrm{~mL} 1 \mathrm{x}$ Binding Buffer and capture in the same tube.

38 Centrifuge the single cell suspension for $\because 400 \times \mathrm{gg}, 4^{\circ} \mathrm{C}, 00: 05: 00$, and discard supernatant.

$\because$

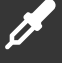

39

Resuspend cell pellet in $₫ 0.5 \mathrm{~mL}$ DPBS, and count cells.

\section{Cell Counting of COVID Samples (10x)}

40 Add $\triangle 0.05 \mathrm{~mL}$ sample I $0.05 \mathrm{~mL}$ DPBS, and $\triangle 0.005 \mathrm{~mL}$ Solution 13 to a $1.5 \mathrm{~mL}$ centrifuge tube, incubate for

00:02:00 at $8^{\circ}$ Room temperature

41

Add $\triangle 0.1 \mathrm{~mL}$ BD Cytofix Fixation Buffer to the samples and incubate $00: 30: 00, \quad \nexists^{\circ}$ Room temperature , and protect from light.

42 Aliquot $\triangle 0.01 \mathrm{~mL}$ sample to the well of a NC-Slide A8 and count on the NC-3000. 

$\%$ viable

\section{X Encapsulation}

44 Follow the appropriate 10X protocol (Chromium Next GEM Single Cell 3' Reagent Kits v3.1 User Guide - Rev D) for encapsulation of cells from the airway sample. 